\title{
APLICAÇÃO DA METODOLOGIA DE ENFERMAGEM NO CUIDADO DE UM PACIENTE
}

Eni de Jesus Rolim*

INTRODUÇÃO

Êste trabalho contém o relato de nossa retoma da com pacientes adultos após termos trabalhado durante trés anos iniciais de profissão num hospital pediátrico.

Em razāo de uma atividade docente na Escola de Enfermagem da USP, nas disciplina de Fundamentos de Enferma gem, procuramos aplicar a nova metodologia de Enfermagem, nes ta ensinada, à prática hospitalar.

Escolhemos uma paciente recém-admitida, inter nada numa enfermaria de 4 leitos, portadora de paralisia dos membros inferiores, como consequencia de aracnoidite.

Cuidamos dessa paciente durante 4 semanas, das 7 às 12 horas, de segunda a sexta feira.

Queríamos atingir os seguintes objetivos:

a) pôr em prática a nova metodologia de enfermagem e testar nossa capacidade de executá-la;

b) verificar nossas reaçōes frente ao paciente adulto e o resul tado dêsse contato;

c) confirmar a viabilidade de aplicação do plano de cuidados nu ma clínica onde êle não é aplicado sistemàticamente.

Dentro do esquema proposto a assistência de en fermagem foi iniciada por levantamento de dados, através do His tórico de Enfermagem.

* Auxiliar de Ensino de Fundamentos de Enfermagem. 
Identificados os problemas partimos para a ela boração do diagnóstico de enfermagem, elemento básico pã.ra o planejamento e execução do plano de cuidados de enfermagem.

Traçado o plano de cuidados para 24 horas e ob tida a colaboraçäo da chefia e da equipe de enfermagem, iodos os elementos da enfermaria foram orientados a atenderem ac planr. proposto. Conseguido êsse intento, o plano de cuidados foi anexs. do à papeleta da paciente.

\section{HISTORICO DE ENFERMAGEM}

M.S.B. tem 50 anos, é solteira, nascide nuniz cidade do interior, órfā de pai e māe; reside com uma irmá cas?. da, em casa de sua propriedade, na Vila Pompéia, Capital.

Sua casa é de tijolos, com 4 peças; dispõe de lur elétrica, água encanada, esgôto, gás e bons meios de comunic?. ção (ônibus, telefone, rádio e televisão).

Católica praticante, antes de adoecer näo perdij. missa aos domingos. Tinha bom relacionamento com os vizilinca e gostava de sair a passeio ou para compras. Enquanto havia $\$ 0$. brinhos pequenos, auxiliava a irmā a cuidar deles.

Tomava suas refeiçōes às $7,11,14$ e 18 ìcras. em pequena quantidade, mas completa nos alimentos nutritivos. Durante o dia o seu trabalho era bordar, ofício com o qual auxiliá va na manutenção da casa. Nas horas de lazer lia revistas, jč̣: nais e romances, ouvia música e via televisão. A noite dormifi aproximadamente 8 horas, num quarto exclusivamente seu.

Não éra hábito seu fazer contrôle médieo u odontológico periódico até o dia em que começou a sentir dores pe lo corpo e dificuldade em caminhar. Consultou então, vários mé dicos e um dêles submeteu-a a uma laminectomia, que nãu trúuxe resultados satisfatórios. Isso a trouxe novamente à consulta.

Nesta altura tivemos oportunidade de iniciar o trabalho proposto. Nāo houve problemas de relacionaments gra cas à sua comunicabilidade. 
A doença impediu-a de andar, interferindo nos seus passeios e também no seu trabalho, que deixou de executar. Não se alteraram, porém, seus hábitos de higiene. Contiüuou a tomar seu banho diário, a escovar os dentes após as refeiçōes, a lavar a cabeça uma vez por semana, com a ajuda dos familiares. Nāo abandonou o uso do desodorante e pó de arroz, muito do sen? agrado. No exame físico, por nós realizado na sua admissão, ol tivemos os seguintes resultados:

1. Revestimento cutâneo-mucoso e anexos:

a) Cabelos - curtos, branco e limpos;

b) Pele - sêca, sem sujidade ou lesāo, flácida;

c) Unhas - das maōs, curtas e limpas, dos pés, curtas duras e espessas;

d) Sobrancelhas e cúlios - em pequena quantidade, nāo depila as sobrancelhas. Hipertricose no rosto.

2. Orgãos dos sentidos:

a) Audição - orelhas normais, com orifícios para brincus, acui. dade normal;

b) Olfação - normal, fossas nasais limpas;

c) Cavidade bucal - língua normal

Prótese na arcada superior em boas conci çōes higiênicas;

d) Visão - míope, não consegue ler sem óculos, conjuntivà $E$ córnea normais;

e) Tacto - ausência de sensibilidade nos MMII até a região lon: bar.

3. Pescoço - Cicatriz operatória de tireoidectomia.

4. Tronco

a) Anterior - Pele flécida. Mamas sem nódulos, mamilos nor mais. Cicatriz umbilical retraída; 
b) Posterior - nódulo volumoso na altura da 1a vértebra dorsal. Cicatriz de laminectomia na região lombar. Escaras: uma de $3 \mathrm{~cm}$. de diâmetro, jả cicatrizada, na regiāo lombar. Ou tra em fase de cicatrização na região sacral e a terceira no glúteo $\mathrm{D}$ com $1,5 \mathrm{~cm}$. de diâmetro.

5. Membros superiores

a) Mobilidade normal

b) Flacidez muscular

c) Rêde venosa visível sem garrote

d) Deltóide flácido, mas, normal mente desenvolvido

6. Membros inferiores
a) Só move a articulação coxo-femoral
b) Possui sensibilidade térmica e dolorosa em todo o membro
c) Flacidez muscular generalizada
d) Ausência de pêlos
e) Pés equinos - sem movimentos voluntários
f) Micose no 2 artelho do pé direito

7. Genitais e ânus
a) Genitais externamente normais, com presença de poucos pê los, de distribuição normal para o sexo. Sonda vesical de demora tipo Fowley
b) Ânus - resfriamento do esfincter anal, presença de hemor róidas; defecaçāo involuntária

8. Sinais vitais
a) Temperatura - 36, 49 C
b) Pulso-92, rítmico, cheio, medianamente tenso
c) Respiração - 24 movimentos, rítmica, sem ruídos
d) Pressão Arterial - $13 \times 8 \mathrm{~mm} \mathrm{Hg}$

9. Queixas
a) Dor da cintura pélvica aos pés com formigamento e ardor
b) Paralisia dos MMII 
Impressōes sobre a paciente - Aceita bem a in ternação, como um meio de livrar-se, através de cirurgia, da dor que a incomoda. Não aborda, nem permite que seja abordado o problema da paralisia.

LEVANTAMENTO DOS PROBLEMAS E DIAGNOSTICO DE EN FERMAGEM

1. ENUMERAÇÃO DOS PROBLEMAS ENCONTRADOS

a) Paralisia dos MMII com dificuldade de movimentação;

b) Incontinência urinária e fecal (sonda vesical);

c) Escara de decúbito no glúteo $\mathrm{D}$ e regiāo sacral;

d) Repulsāo a tomate, rabanete e banana;

e) Dores nos MMII;

f) Visão afetada para objetos próximos;

g) Incapacidade de fazer parte de sua higiene corporal, pudor em relaçāo à região pudenda (sente vergonha);

h) Precisa de mudança de decúbito e de outros cuidados, mas não solicita de médo de ver "cara feia";

i) Normalmente sente muito calor.

Pelos problemas acima levantados podemos fa zer um quadro das necessidades não atendidas e do grau de depen déncia de enfermagem como veremos a seguir:

2. Necessidades não atendidas

Dependência

1. Locomoção (exercício)

Parcial

2. Eliminação urinária e intestinal

Total

3. Integridade cutânea

Parcial

4. Alimentação

Parcial

5. Conforto e alívio de dores

Total

6. Comunicação sensorial (tactil

7. Cuidado corporal (visual

Parcial

8. Independência

Parcial

Parcial

9. Regulaçāo térmica

Parcial

10. Terapêutica

Total 
Com êsses dados partimos para o

DLAGNOSTICO DE ENFERMAGEM

A paciente depende da enfermagem:

1. parcialmente para o atendimento das seguintes necessidades:
a) locomoçāo (exercício);
b) integridade cutânea;
c) alimentação;
d) comunicação sensorial;
e) cuidado corporal;
f) independência;
g) regulação térmica;

2. Totalmente para o atendimento de:
a) eliminaçāo urinária e intestinal;
b) terapêutica;
c) confôrto e alívio de dores.

De acôrdo com êsse diagnóstico elaboramos o primeiro plano de cuidados:

PALNO DE CUIDADOS

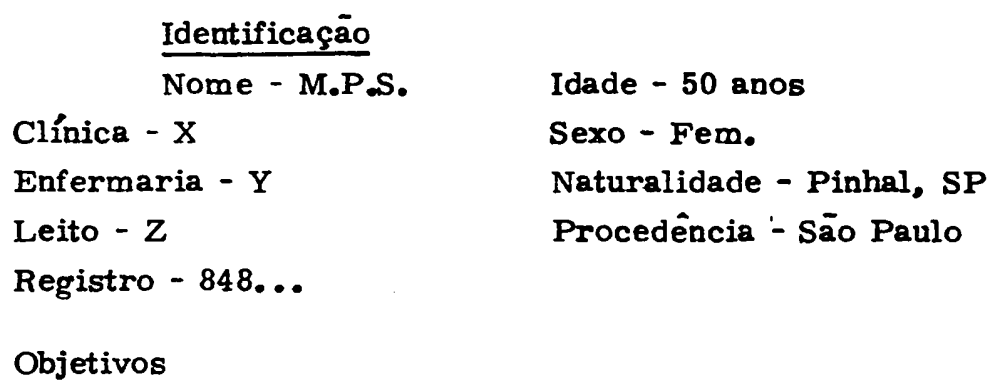

1. Dispensar cuidados de enfermagem ao doente com paralisia dos MMII acompanhada de incontinência urinária e fecal;

2. Promover fechamento de escara e prevenir aparecimerito de outras;

3. Evitar dor nos MMII. 
CUIDADOS DE ENFERMAGEM

\section{CUIDADOS}

1. Banho no leito
HORÁRIO

8

Cuidado com a pele

2. Higiene oral (prótese

- na arcada superior)

3. Curativo de escara e prevenção da forma çāo de novas.
8. 12

18. 21

8

RECOMENDAÇÖES

Deixá-la lavar-se até onde pode e pentear-se.

Oferecer desodorante. Deixá-la sòzinha durante a higiene íntima.

Massageá-la com "Cold cream".

Oferecer o materiai nara que faça sòzinha sua $\mathrm{ri}$ giene.

Fazer curativo passando benjoin nas bordas e líqu: do de Dakin na lesãc. Prote ger a pele do glúteo E' corn. benjoin.

4. Mudança de decúbito e cuidado com os

8.11 .14 . Manter os MMII em peque MMII 17.20 .23 . na elevaçāo. Apoiar os pés comalmofadas. Fazer mag. sagem por alisamento leve e ginástica passiva.

5. Cuidado com a sonda 8.14 .20$. vesical

6. Cuidado com a elimi nação intestinal.

2. 5

7. Cuidado com a regula çāo térmica

8. Alimentação
Fazer lavagem da sonda vs: sical com ácido acético á 5\%. Trocar a sonda cada 1 dias. Observar e trocer $\varrho$ cama se necessáric.

Fazer lavagem externa à. pós defecação.

Nảo colocar cobertor na ca ma.

8. 14. 17. Não gosta de tomate, raba 20 nete e banana. Se possível levá-la à mesa para co mer. 


\section{CUIDADOS}

9. Sono è repouso

10. Atenção

11. Medicaçāo

12. Local das injeçōes e cuidados

13. Recreação
HORARIO

RECOMENDAÇÕES

Deixá-la dormir após o al môço.

Oferecer-se para peque nos cuidados a curtos in tervalos.

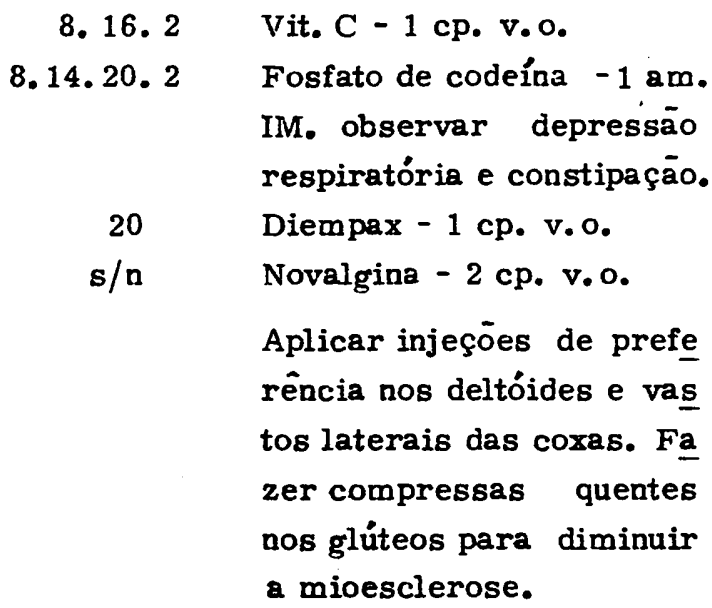

Ler para a paciente o que seja do seu agrado. Pas seio no solário em cadeira de rodas. Rádio-audiçāo.

Avaliaçāo do plano de cuidados

O plano de cuidados atendeu perfeitamente às ne cessidades da paciente, à exceçāo dos ítens 4, 10 e 12, por moti vos alheios á nossa vontade, e que analisaremos nas conclusōes.

Êsse plano foi utilizado durante duas semanas, com mudanças apenas da medicaçāo, sendo suspensos todos os me dicamentos a exceção da Vitamina $C$; foi feita prescriçāo de Sosse gon, 1 ampola cada 6 horas. 


\section{EVOLUÇÃo}

Como não havia data marcada para a cirurgia prevista para a paciente, procuramos fazer um preparo psicológi co a longo prazo. Êste constituiu principalmente em alertá-la e em convencế-la de que não poderia mais andar. Mas, percebemos logo que ela sabia disso, pois dizia sempre que esperava não ter mais dores após a cirurgia.

A cirurgia foi marcada num sábado, em nossa au sência, para daí a dois dias. Quando cheguei ao hospital, na se gunda feira, a paciente já estava na maca; encontrava-se choró sa. Procurei acalmá-la no que tive êxito e a acompanhei até a sa la de cirurgia, onde permaneceu por 5 horas $\epsilon$ meia.

Dessa exposição pode-se concluir que não me foi possível fazer um plano de cuidados para o pré-operatório ime diato.

No pós operatório ela se manteve por 3 dias na sala de recuperação e o plano de cuidados para êsse tempo foi 0 abaixo descrito.

\section{Problemas levantados}

Além dos anteriormente citados acrescentaramse: incisāo cirúrgica na regiāo lombar; prevenção de complica çōes; restriçāo de movimentos e decúbito especial para a cirur gia feita (decúbito dorsal em superfície plana).

As necessidades não atendidas eram as mesmas, acrescentando-se, apenas, maior dependéncia para o atendimento das necessidades de integridade cutânea e de exercício.

Ao diagnóstico de enfermagem foi incluído: de pendência total em relação à integridade cutânea e exercício.

\section{PLANO DE CUIDADOS PÓS OPERATÓRIO}

Objetivos:

1. Orientação psicológica para que compreenda a sensação da dor residual nos MMII; 
2. Promover fechamento de escara e evitar formação de ou tras;

3. Prevenir complicação pós-operatória;

4. Prevenção de anquilose e atrofia dos MMII por meio ủa tisio terapia.

\section{Cuidados de enfermagem}

CUIDADOS

1. Banho no leito

2. Higiene oral

3. Cuidados com a regulação térmi ca

4. Exercício 8

5. Curativo de esca ra 8. $\begin{aligned} & 12 . \\ & 20\end{aligned}$

HORARIO

8

Deixá-1a lavar-se cnde py: der e pentear-se sùzinha. Afastar-se enquanto e].: faz sua higiene íntima.Mas. sagem da pele com "coldcream". Oferecer desodi rante.

Oferecer material par: que possa fazế-la.

Nāo colocar cobertur ne cama.

Massagem nos MMii e gi nástica passiva para. evi tar edema e anquilsse. Ele vação.

8 Lavar a lesāo com iĺquido de Dakin, passar tintura de Benjoin nas bordais, pr; teger corn gase.

6. Sonda vesical

8. 14. 20 2

7. Eliminação intes tinal
Lavar com KMnO a $1 / 20000$. Trocar a sonda cada 4 dias. Observar e trocar $\approx$ móvel da cama. Fazer lavažem externa se necessário. 
CUIDADOS

8. Alimentação

8. 11. 14

17. 20

HORÁRIO

RECOMENDAÇŌES
9. Mudança de de cúbitos

8. 11.14

17. 20.23

2.5
10. Sono e repouso

11. T.P.R.

12. Compressas quen tes nos deltóides

8. 14 Observar e anotar anormi? 20. 2 lidades em especial temp品 ratura.

8.16 Fazer compressas nùo muj to quentes, pois tem baixa tolerância ao calor. Msse? gear o local após as corii pressas. Nāo aplicar inję çōes neste local.

13. Medicaçāo

$\mathbf{s} / \mathbf{n}$

Sossegon 1 ampola Iivil.

Avaliaçāo do plano de cuidados

A exceçāo dos ítens 9 e 12, os demais forau cumpridos atendendo às necessidades da paciente. Os motivcis da nāo observância foram alheios à nossa vontade e serão coniente dos posteriormente.

Evolução

Por ocasião da alta a paciente estava com a feri da operatória cicatrizada e com as escaras em fase de cicatriza ção. 
Apresentava boa disposiçāo psicológica em rela çāo à sua deficiência de deambulação.

Nos últimos dias de sua permanência no hospi tal, procuramos ensinar-ihe como cuidar de si, quando estivesse em casa. Isso foi-lhe ensinado para que transmitisse aos familia res, , com os quais nosso contato foi mínimo.

Ela demonstrou muito interêsse e até nos inter rogava sôbre como proceder no cuidado com a sonda vesical, o curativo das escaras e os exercícios a serem feitos.

Ao despedir-se nos agradeceu muito e comentou favoràvelmente sôbre sua permanência no hospital.

\section{CONCLUSŌES}

Após as 4 secranas de prática em campo pude mos avaliar o trabalho em função dos objetivos propostos.

Além da paciente sob nossos cuidados, pudemos observar outros com problemas neurológicos.

Em primeiro lugar sentimos que, com o pacien te adulto, é menor a necessidade de inferéncia, pois, desde que captemos sua confiança êle nos põe a par de seus desejos, temo res, angústias e alegrias.

A criança, quando já capaz de se comunicar, não tem inibição e expressa realmente o que está sentindo.

Por cutro lado o adulto nem sempre é objetivo, usa de meias palavras ou se queixa de algo sem muita importância apareate, quando sua angústia está ligada a problemas bem mais graves do que aquêle revelado.

A aplicaçāo da nova metodologia de enfermagem nos permitiu constatar que seu uso traz vantagens para o paciente e para a equipe de enfermagem.

Como vantagens para o paciente salientamos:

individualização do paciente;

atendimento de suas necessidades em função dos problemas identificados; 
segurança do paciente em razāo dos cuidados recebidos;

Para a equipe de Enfermagem podemos apontar as seguintes vantagens:

conhecimento mais profundo do paciente;

identificação dos seus problemas, em função de suas necessi dades básicas;

planejamento do trabalho, de forma a solucionar os proble mas encontrados;

facilidade na avaliação da evolução do paciente;

segurança da equipe pela utilização do método científico pa ra a solução dos problemas do paciente.

A aplicação dos novos métodos de enfermagem numa clínica em padrōes tradicionais na assistência de enferma gem nos permitiu observar fatos que relataremos a seguir.

Seria viável a aplicação dos novos métodos de enfermagem numa clínica onde ainda nāo foram adotados tais mé todos; essa aplicação, porém, é muitas vézes prejudicada, seja porque o pessoal de enfermagem ainda nāo está preparado para is so ou porque, por falta de planejamento, o pessoal é deficiente em número.

Apesar do pessoal estar consciente de nosso tra balho; houve, muitas vêzes, falha nas realizaçōes dos cuidados, como pudemos constatar na mudança dos decúbitos, na aplicação de compressas e na dispensa de atenção à paciente.

O nosso pleno de cuidados foi feito para 24 horas; e notamos que as falhas maiores aconteceram durante os plantões noturnos.

A que se deve êsse resultado:

Pessoal nāo habilitado?

Pouco Pessoal?

Desinterêsse no conhecimento e execução dos cuidados pres critos? 
Rejeição à introdução de novos métodos de trabalho?

Não temos respostas objetivas a essas pergun tas, pois nāo foi possível controlar a situaçāo e concluir a respei to.

Além das dificuldades que tivemos, entretanto, das falnas que cometemos e de outras fora de nosso alcançe, repu tamos a experiência como de grande valor para nós e para outros que dela tomem conhecimentc.

Acreditamos que essas tentativas e o desejo fi: me que temos de tornar a Enfermagem uma profissão objetiva, ri: cional e científica nos levará, a curto ou a longo prazo, a at.ingir nosso ideal de proporcionar ao doente tudo o que de melhor tiver mos, a fim de atender às suas necessidades básicas.

\section{BIBLIOGRAFIA}

1. CARVALHO, ANAYDE C. DE - Plano de cuidados de Eúferms gem como uma das funçōes da enfermeira chefe. Kevist: da Escola de Enfermagem da USP, 2 (1): 108-117, março. 1968.

2. FUERST, ELINOR, V. - Princípios fundamentales de Enierm ria. México, La Prensa Medica Mexicana, 1966.

3. HORTA, WANDA DE AGUIAR - A observaçāo sistematizeła n? identificaçāo dos problemas de enfermagem em seus asper: tos físicos. Tese de docência livre. São Paulo, RUjuP, Ser viço de Documentaçāo, 1968.

4. HORTA, WANDA DE AGUIAR - Notas preliminares sôre His tórico de enfermagem. Revista da Escola de Enfermegera da USP. 3 (2), set., 1969 (no prelo).

5. MORAES, ESTHER - Um plano de Cuidados de Enfermagem. Revista da Escola de Enfermagem da USP, 1 (1): $93-111$, outubro, 1967.

6. NATIVIDADE, EDITH, M. - Como escrever um trabalhn cientí fico. Revista do Hospital das Clínicas, 28 (1): 77-30, jan./ fev., 1969. 
7. WALSH, JACQUELINE P. - Injured ou the road. Nursing Times. $65(18)+553-554$, maio, 1969 .

ROLIM, E.J. - Aplicação da Metudo logia de enfermagem no cuidado de um paciente. Rev. da Esc. de Enf. USP, 4 (1-2):81-9.5 mâr set.s 1970 . 